\title{
Eficiência no Uso da Água e Interferência de Plantas Daninhas no Meloeiro Cultivado nos Sistemas de Plantio Direto e Convencional ${ }^{1}$
}

\author{
Water use Efficiency and Weed Interference in Melon Crop under Conventional and No-Tillage \\ Systems
}
TEÓFILO, T.M.S. ${ }^{2}$, FREITAS, F.C.L. ${ }^{3}$, MEDEIROS, J.F. ${ }^{4}$, FERNANDES, D. ${ }^{5}$, GRANGEIRO, L.C. ${ }^{6}$, TOMAZ, H.V.Q. ${ }^{7}$ e RODRIGUES, A.P.M.S. ${ }^{7}$

\begin{abstract}
RESUMO - Com o objetivo de avaliar o efeito dos sistemas de plantio direto e convencional e estratégias de manejo de plantas daninhas na economia de água de irrigação na cultura do melão (Cucumis melo), conduziu-se um experimento na horta didática do Departamento de Ciências Vegetais da Universidade Federal Rural do Semiárido, em Mossoró-RN, utilizando o delineamento experimental de blocos casualizados, no esquema de parcelas subdivididas. Nas parcelas foram avaliados dois sistemas de plantio (plantio direto e convencional) e, nas subparcelas, três sistemas de manejo de plantas daninhas (cobertura com filme de polietileno, mantido no limpo por meio de capinas e testemunha sem capinas). Avaliaram-se a densidade e a massa seca das plantas daninhas aos 30 dias após o transplante, a produtividade comercial e total e o consumo diário de água. O manejo da água foi realizado mediante a curva característica de água no solo para cada sistema de plantio a 15 e $30 \mathrm{~cm}$ de profundidade, e o controle da lâmina de água foi feito com base na leitura diária de um conjunto de tensiômetros instalados nas mesmas profundidades, de modo que se mantivesse a umidade do solo sempre acima de $75 \%$ da água disponivel total. A partir da produtividade e do consumo de água, determinou-se a eficiência no uso da água (EUA), dada em $\mathrm{kg} \mathrm{m}^{-3}$. Verificou-se que o sistema de plantio direto na palha reduziu a densidade populacional e a massa seca acumulada pelas plantas daninhas em 86,7 e 61\%, respectivamente, em relação ao plantio convencional, e a interferência destas reduziu a produtividade comercial em $100 \%$ no plantio convencional e $36,5 \%$ no direto. A cobertura do solo com filme de polietileno no plantio convencional e no plantio direto e a palhada no plantio direto reduziram o consumo de água em $23 \%$ (388,8 $\left.\mathrm{m}^{3} \mathrm{ha}^{-1}\right), 21 \%\left(363,0 \mathrm{~m}^{3} \mathrm{ha}^{-1}\right)$ e 13\% $\left(215,0 \mathrm{~m}^{3} \mathrm{ha}^{-1}\right)$, respectivamente, em relação ao tratamento com capinas no plantio convencional. A cobertura do solo com filme de polietileno nos dois sistemas de plantio ou com cobertura morta no plantio direto aumentou a eficiência no uso da água em relação ao solo sem cobertura. No tratamento sem capinas no sistema de plantio convencional, além da perda total na produtividade comercial, a interferência das plantas daninhas aumentou o consumo de água em 9,6\%.
\end{abstract}

Palavras-chave: Cucumis melo, economia de água, filme de polietileno, cobertura morta.

\begin{abstract}
The objective of this work was to evaluate the effect of the conventional and no-tillage systems and weed management strategies on water use efficiency in melon crop (Cucumis melo). Thus, an experiment was carried out in a randomized block design in split-plots in Mossoró-RN. The plots were constituted of two tillage systems (conventional and no-tillage) and the sub-plots of three weed management systems (plastic mulch, weeding, and no weeding). Density and dry weight of the weeds at 30 days after transplanting, commercial and total yield and daily consumption of
\end{abstract}

1 Recebido para publicação em 22.9.2011 e aprovado em 9.6.2012.

2 Enga-Agr ${ }^{\mathrm{a}}$., M.Sc., Agrícola Famosa-Mossoró-RN, <taliane@agrfamosa.com.br>; ${ }^{3}$ Professor Adjunto do Dep. de Ciências Vegetais - UFERSA, <fclaudiof@yahoo.com.br>; ${ }^{4}$ Engo-Agr ${ }^{\circ}$. , D.Sc., Dep. de Ciências Ambientais, UFERSA, <francismar@ufersa.edu.br>; ${ }^{5}$ Licenc. em Ciências Agrárias, M.Sc., Fitotecnia, UEPB, < doris_uepb@hotmail.com>; ${ }^{6}$ Professor Adjunto do Dep. de Ciências Vegetais, UFERSA, <leilson@ufersa.edu.br>; ${ }^{7}$ Eng$^{0}-A g r{ }^{\circ} .$, M.Sc., Agristar-Mossoró-RN, <halen.vieira@agristar.com.br>; ${ }^{8}$ Mestranda em Fitotecnia, UFERSA, <anapaulamsr@hotmail.com>.

Planta Daninha, Viçosa-MG, v. 30, n. 3, p. 547-556, 2012 
water were evaluated. Irrigation management was performed by the characteristic soil water curve for each cropping system at 15 and $30 \mathrm{~cm}$ of depth and water control by daily reading a set of tensiometers installed to keep the soil above 75\% of field capacity. Water use efficiency (USA), given in $\mathrm{kg}$ of fruit per $\mathrm{m}^{3}$, was determined based on the crop's yield and water consumption. It was found that the no-tillage system reduced weed density and dry matterin 86.7 and 61\%, respectively, compared to conventional tillage, and weed interference reduced commercial yield by $100 \%$ under conventional tillage and $36.5 \%$ under no-tillage. Soil with plastic mulch under no-tillage and conventional systems, and straw mulching under no-tillage reduced water consumption by 23\% $\left(388.8 \mathrm{~m}^{3} \mathrm{ha}^{-1}\right), 21 \%\left(363.0 \mathrm{~m}^{3} \mathrm{ha}^{-1}\right)$ and 13\% (215.0 $\left.\mathrm{m}^{3} \mathrm{ha}^{-1}\right)$, respectively, compared to the weeding treatment under conventional tillage. Soil with plastic mulch under the two tillage systems, or straw mulching under no-tillage increased the efficiency of water use from the ground without cover. In the no-weeding treatment under conventional tillage, weed interference caused total productivity loss and increased water consumption by $9.6 \%$.

Keywords: Cucumis melo, water saving, plastic mulch, straw mulch.

\section{INTRODUÇÃO}

Entre as hortaliças tropicais, o melão (Cucumis melo) é a que tem demonstrado expansão mais significativa nas duas últimas décadas, especialmente nas regiões semiáridas do Nordeste brasileiro, com destaque para os Estados do Ceará e Rio Grande do Norte. Nessa região, o cultivo é realizado principalmente nos períodos mais secos do ano, com irrigação localizada da água por gotejamento, que, segundo Batista et al. (2009), aumenta a eficiência no uso da água e reduz a incidência de doenças foliares e a proliferação de plantas daninhas, por evitar que a parte aérea das plantas e a faixa entre as fileiras de plantio sejam molhadas.

A necessidade de água nas culturas é expressa, normalmente, pela taxa de evapotranspiração, que varia ao longo do ciclo em função da fase fenológica da planta e depende das condições meteorológicas e da disponibilidade hídrica do solo (Doorembos \& Kassan, 1979). A quantidade de água utilizada depende da eficiência do método de irrigação adotado (Batista et al., 2009), do controle da lâmina aplicada (Allen et al., 1998) e da capacidade de armazenamento de água no solo, que é favorecida pelo aumento da infiltração e, principalmente, pela redução da taxa de evaporação, por meio da cobertura do solo com materiais sintéticos ou de origem vegetal. Freitas et al. (2004) verificaram que a perda de água por evaporação no solo sem cobertura foi três vezes superior à do solo com cobertura morta.
A utilização da cobertura morta é um dos princípios nos quais se baseia o sistema de plantio direto na palha, assim como a rotação de culturas e a ausência do revolvimento do solo. Esse sistema tem sido utilizado em larga escala em culturas como soja e milho; nos últimos anos, diversos trabalhos têm sido conduzidos com êxito no cultivo de hortaliças, como os de Tomaz (2008) e Fernandes (2010), com melão, e Marouelli et al. (2006) e Silva et al. (2009), com tomate.

A cobertura do solo de origem vegetal pode ser formada pelos próprios restos vegetais da cultura anterior ou pelo cultivo de espécies apropriadas para formação de palhada, como a Brachiaria sp., que pode ser cultivada em consórcio com culturas anuais, como o milho (Freitas et al., 2008) ou feijão (Silva et al., 2006), no intuito de produzir palhada para o plantio direto. Além de reduzir a taxa de evaporação de água no solo, o sistema de plantio direto protege o solo da ação da erosão e reduz a incidência de plantas daninhas na cultura do meloeiro, com produção equivalente à do preparo convencional do solo (Tomaz, 2008).

Outro importante fator que afeta o consumo de água e a produtividade das culturas é a interferência de plantas daninhas. Segundo Tomaz (2008), na cultura do melão, quando não controladas, as plantas infestantes podem proporcionar perdas de até $100 \%$ na produtividade de frutos comercializáveis, dependendo do grau de infestação. 
O controle das plantas daninhas no meloeiro vem sendo realizado utilizando diversos métodos, variando de acordo com o nivel tecnológico e a capacidade de investimento do produtor. Todavia, a técnica que vem sendo utilizada com maior frequência é o filme de polietileno, que, além de promover o controle das plantas daninhas, reduz a perda de água por evaporação. Por outro lado, tem custo elevado, tanto pela matéria-prima quanto pela mão de obra na sua colocação (Silva et al., 2007).

Diante do exposto, este trabalho teve como objetivos avaliar o efeito dos sistemas de plantio direto e convencional e estratégias de manejo de plantas daninhas sobre a produção e a eficiência de uso da água na cultura do melão.

\section{MATERIAL E MÉTODOS}

O experimento foi conduzido no período de outubro a dezembro de 2008, na horta didática da Universidade Federal Rural do Semiárido (UFERSA), no município de Mossoró-RN, em solo classificado como Argissolo VermelhoAmarelo eutrófico (Embrapa, 1999). Da área experimental foram retiradas amostras, na profundidade de $0-20 \mathrm{~cm}$, para realização de análise química e física, obtendo-se os seguintes resultados: análise química: $\mathrm{pH}$ (água 1:2,5) $=8,70 ; \mathrm{Ca}=3,80 \mathrm{cmol}_{\mathrm{c}} \mathrm{dm}^{-3}, \mathrm{Mg}=$ $1,47 \mathrm{cmol}_{\mathrm{c}} \mathrm{dm}^{-3}, \mathrm{~K}^{+}=166,3 \mathrm{mg} \mathrm{dm}^{-3}, \mathrm{Na}=$ $99,7 \mathrm{mg} \mathrm{dm}^{-3}, \mathrm{Al}^{3+}=0,00 \mathrm{cmol}_{\mathrm{c}} \mathrm{dm}^{-3}$ e $\mathrm{P}=$ $122,1 \mathrm{mg} \mathrm{dm}^{-3}$; e análise física: areia total = $0,88 \mathrm{~kg} \mathrm{~kg}^{-1}$, silte $=0,08 \mathrm{~kg} \mathrm{~kg}^{-1}$, Argila $=$ $0,03 \mathrm{~kg} \mathrm{~kg}^{-1}$, densidade aparente $=1,22 \mathrm{~kg} \mathrm{dm}^{-3}$, densidade real $=2,58 \mathrm{~kg} \mathrm{dm}^{-3}$ e porosidade total $=52,67 \%$. Durante o período experimental não houve precipitação pluvial; os dados de temperatura, umidade relativa do ar, velocidade do vento, radiação global e evapotranspiração de referência estão apresentados na Figura 1.

O experimento foi conduzido no esquema de parcelas subdivididas, distribuídas no delineamento de blocos casualisados, com quatro repetições. Nas parcelas foram avaliados dois sistemas de preparo do solo (plantio direto e plantio convencional) e, nas subparcelas, três sistemas de manejo de plantas daninhas (cobertura com filme de polietileno, tratamento mantido no limpo por meio de capinas e testemunha sem capinas).
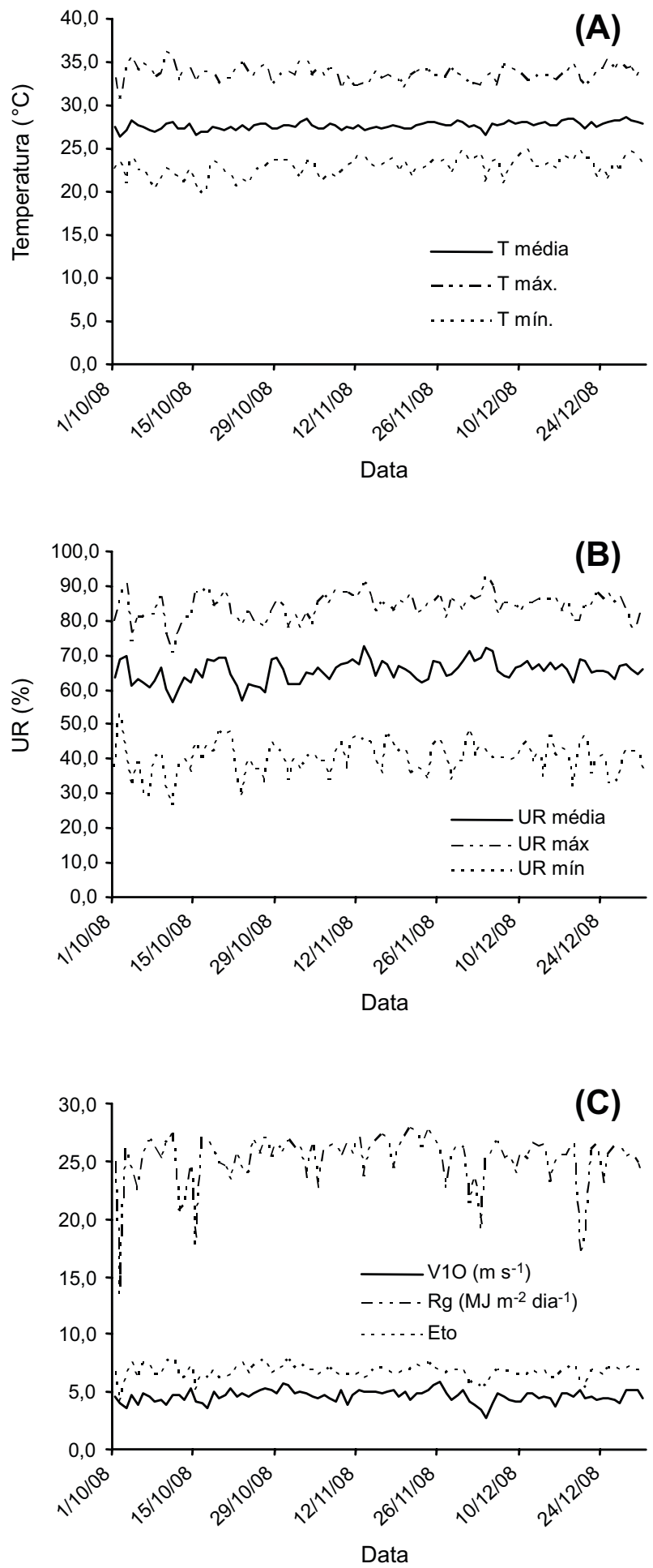

Figura 1 - Temperaturas máxima (Tmáx.), mínima (Tmín) e média (Tmédia) (A), umidade relativa do ar máxima (UR máx.), mínima (URmín) e média (URmédia) (B), velocidade do vento a $10 \mathrm{~m}$ de altura (V10), radiação global (Rg) e evapotranspiração de referência (ETo) (C) durante o período experimental. Mossoró. 2008. (Fonte: Instituto Nacional de Meteorologia - INMET).

Planta Daninha, Viçosa-MG, v. 30, n. 3, p. 547-556, 2012 
Nas parcelas de plantio direto, para obtenção da palhada, foi realizado em fevereiro de 2008, no início do período chuvoso, o plantio da cultura do milho em consorciação com Brachiaria brizantha. A semeadura da forrageira foi realizada na linha do milho por meio de plantadeira adubadeira manual, no espaçamento de 0,70 m entre fileiras e $0,40 \mathrm{~cm}$ entre covas, utilizando-se $3,0 \mathrm{~kg} \mathrm{ha}^{-1}$ de sementes viáveis. Após a colheita do milho, a forrageira cresceu livremente até o mês de julho, que corresponde ao final do periodo chuvoso, quando foi feita a dessecação com o herbicida glyphosate na dose de $1,90 \mathrm{~kg}$ ha ${ }^{1}$. A massa seca de palhada verificada na ocasião do transplantio, por meio de amostragens em quadrados de $0,25 \mathrm{~m}^{2}$, foi de $6 \mathrm{t} \mathrm{ha}^{-1}$. Nas parcelas com plantio convencional, o solo foi preparado por meio de aração e duas gradagens, realizadas na semana anterior ao transplantio das mudas de melão.

A unidade experimental foi constituída por uma fileira de plantas de $5,40 \mathrm{~m}$ de comprimento, espaçada de $1,80 \mathrm{~m}$. A área útil considerada foi de $4,00 \mathrm{~m}$ de fileira, correspondendo a 10 plantas centrais da fileira. Utilizou-se o híbrido de melão-amarelo 60/01 (Topseed) com mudas produzidas em bandejas de polietileno com 200 células e substrato comercial para hortaliças. O transplantio foi realizado aos 12 dias após a semeadura, no espaçamento de $1,80 \mathrm{~m}$ entre fileiras e $0,40 \mathrm{~m}$ entre plantas. Por ocasião do transplantio, foi feita adubação na cova, equivalente a $200 \mathrm{~kg} \mathrm{ha}^{-1}$ de $\mathrm{P}_{2} \mathrm{O}_{5}$ usando como fonte o superfosfato simples. As adubações de cobertura foram realizadas via água de irrigação, utilizando-se 188,0 $\mathrm{kg} \mathrm{ha}^{-1}$ de $\mathrm{N}, 125,3 \mathrm{~kg} \mathrm{ha}^{-1}$ de $\mathrm{P}_{2} \mathrm{O}_{5}$ e $159,0 \mathrm{~kg} \mathrm{ha}^{-1}$ de $\mathrm{K}_{2} \mathrm{O}$, na forma de ureia, MAP e cloreto de potássio, respectivamente, segundo metodologia adotada por Tomaz (2008).

Foi utilizado o sistema de irrigação localizada por gotejamento, com emissores espaçados de $0,3 \mathrm{~m}$ e vazão de $1,7 \mathrm{~L} \mathrm{~h} \mathrm{~h}^{-1}$. O manejo da água foi realizado com base na curva característica de água no solo para cada sistema de plantio a 15 e $30 \mathrm{~cm}$ de profundidade (Figura 2), de modo que mantivesse o solo com umidade superior a $75 \%$ da água disponivel total; por ocasião das irrigações de cada tratamento, a umidade do solo foi elevada para valores correspondentes a potencial matricial, média nas duas profundidades, de cerca de $-3 \mathrm{kPa}$ (capacidade de campo). Com base nessas informações de lâminas de água aplicadas, determinou-se o consumo diário de água nos diferentes períodos de cultivo do meloeiro, para cada tratamento, em semanas; esse controle do volume aplicado foi feito a partir da segunda semana após o transplantio até próximo à colheita (oitava semana), e o consumo de água foi avaliado pela média diária semanal.

Aos 30 DAT, fez-se avaliação de plantas daninhas, nos tratamentos sem capinas, por meio de duas amostragens em quadrados vazados de $0,50 \mathrm{~cm}$ de lado, por subparcela. As plantas daninhas foram separadas por espécie, contadas e levadas à estufa com circulação forçada de ar a $65{ }^{\circ} \mathrm{C}$ até massa constante.

A colheita dos frutos de melão ocorreu aos 62 dias após o transplantio, quando eles apresentavam teor de sólidos solúveis em torno de 10 Brix. Para isso, foram colhidos os frutos das plantas da área útil, para determinação da produtividade comercial e produtividade total. Foram considerados comercializáveis os frutos com peso superior a $0,90 \mathrm{~kg}$ e sem defeito aparente, conforme metodologia empregada pelas empresas produtoras de melão da região.

A partir da produtividade de frutos comercializável e total $\left(\mathrm{Pt}, \mathrm{kg} \mathrm{ha}^{-1}\right)$ e da quantidade

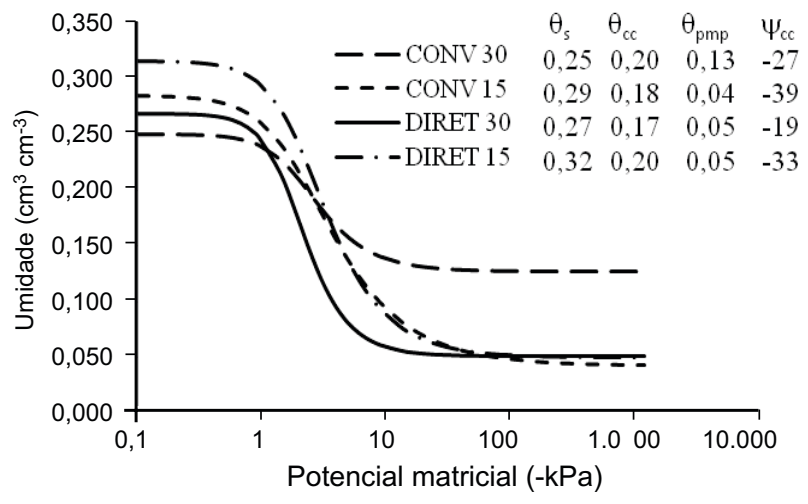

Figura 2 - Curva de característica de água do solo nas profundidades de 15 e $30 \mathrm{~cm}\left(\theta_{\mathrm{s}}=\right.$ umidade do solo no ponto de saturação; $\theta_{\text {cc }}=$ umidade do solo na capacidade de campo; $\theta_{\mathrm{pmp}}=$ umidade do solo no ponto de murcha permanente; $\psi_{\text {cc }}=$ umidade do solo no potencial matricial) nos sistemas de plantio direto e convencional - Mossoró-RN, 2010. 
de água aplicada pela irrigação no ciclo da cultura para cada tratamento $\left(\mathrm{W}, \mathrm{m}^{3} \mathrm{ha}^{-1}\right)$, determinou-se a eficiência de uso de água (EUA, $\mathrm{kg} \mathrm{m}^{-3}$ ), conforme descrito por Doorembos \& Kassan (1979):

$$
\mathrm{EUA}=\mathrm{Pt} / \mathrm{W}
$$

Os dados obtidos foram submetidos à análise de variância, e as médias dos tratamentos, comparadas pelo teste de Tukey a $5 \%$ de significância, pelo programa SAEG. O consumo de água ao longo do ciclo foi submetido à análise de regressão. Na escolha do modelo levou-se em conta a explicação biológica e a significância do quadrado médio da regressão e das estimativas dos parâmetros.

\section{RESULTADOS E DISCUSSÃO}

As principais espécies de plantas infestantes na área, observadas nos tratamentos sem capinas, foram bredo (Talinum paniculatum), milho (Zea mays), tiririca (Cyperus rotundus), caruru (Amaranthus spinosus), trapoeraba (Commelina benghalensis), capim-milhã (Digitaria bicornis) e jitirana (Merremia aegyptia) (Tabela 1).

No sistema de plantio convencional, a espécie com maior acúmulo de massa seca foi o milho, que, apesar de ser uma cultura de grande valor econômico, nessa condição, assume importante papel como planta daninha, pois as sementes não colhidas foram incorporadas ao solo pela aração e gradagem. Posteriormente, elas germinaram e foram favorecidas pela irrigação e fertilização realizada na cultura do meloeiro, tornando-se uma importante espécie competidora devido à sua intensa taxa de crescimento inicial; mesmo em baixa densidade, ela foi responsável por $37,9 \%$ da massa seca total acumulada pelas plantas daninhas. No sistema de plantio direto, como não houve incorporação das sementes ao solo, essa espécie mostrou-se ausente (Tabela 1). Quando se avaliam todas as espécies, verifica-se que o sistema de plantio direto reduziu a densidade e a massa seca acumulada pelas plantas infestantes em 86,7 e $61 \%$, respectivamente, aos 30 dias após o transplantio, em relação ao plantio convencional.

Vidal \& Trezzi (2004) observaram reduções de $41 \%$ de infestação e de $74 \%$ de massa seca total de plantas daninhas comparando as áreas de plantio direto cobertas com palhada, em relação à testemunha descoberta. Na cultura da cenoura, Santos et al. (2011) verificaram que o solo com preparo convencional

Tabela 1 - Densidade das principais espécies de plantas daninhas (plantas $\mathrm{m}^{-2}$ ) na cultura do melão, aos 30 dias após o transplantio. Mossoró-RN, UFERSA, 2008

\begin{tabular}{|c|c|c|c|c|c|c|c|c|c|c|}
\hline $\begin{array}{l}\text { Sistema de } \\
\text { plantio }\end{array}$ & $\begin{array}{l}\text { Sistema de } \\
\text { Manejo }\end{array}$ & $\begin{array}{c}\text { Milho } \\
\text { (Z. mays) }\end{array}$ & $\begin{array}{c}\text { Bredo } \\
(T . \\
\text { paniculatum) }\end{array}$ & $\begin{array}{c}\text { Caruru } \\
(A . \\
\text { spinosus })\end{array}$ & $\begin{array}{l}\text { Jitirana } \\
(M . \\
\text { egiptia) }\end{array}$ & $\begin{array}{c}\text { Trapoeraba } \\
(C . \\
\text { benghalensis })\end{array}$ & $\begin{array}{l}\text { Tiririca } \\
(C . \\
\text { rotundus })\end{array}$ & $\begin{array}{l}\text { Capim- } \\
\text { milhã } \\
(D . \\
\text { bicornis) }\end{array}$ & Outras & Total \\
\hline & & \multicolumn{9}{|c|}{ Densidade (plantas $\mathrm{m}^{-2}$ ) } \\
\hline \multirow{3}{*}{$\begin{array}{c}\text { Plantio } \\
\text { Convencional }\end{array}$} & filme de polietil. & - & - & - & - & - & - & - & - & - \\
\hline & Capinado & - & - & - & - & - & - & - & - & - \\
\hline & Sem capina & $52,9 \mathrm{a}$ & $697,3 a$ & $46,7 \mathrm{a}$ & $11,4 \mathrm{a}$ & $29,5 \mathrm{a}$ & $22,1 \mathrm{a}$ & $24,6 \mathrm{a}$ & $139,4 a$ & $1024 \mathrm{a}$ \\
\hline \multirow{3}{*}{ Plantio direto } & Filme de polietil. & - & - & - & - & - & - & - & - & - \\
\hline & Capinado & - & - & - & - & - & - & - & - & - \\
\hline & Sem capina & $\mathrm{Ob}$ & $97,2 b$ & $1 \mathrm{~b}$ & $1,5 \mathrm{~b}$ & $2,7 b$ & $9 \mathrm{~b}$ & $19,2 \mathrm{~b}$ & $5 b$ & $136 \mathrm{~b}$ \\
\hline & & \multicolumn{9}{|c|}{ Massa seca $\left(\mathrm{g} \mathrm{m}^{-2}\right)$} \\
\hline \multirow{3}{*}{$\begin{array}{c}\text { Plantio } \\
\text { convencional }\end{array}$} & Filme de polietil. & - & - & - & - & - & - & - & - & - \\
\hline & Capinado & - & - & - & - & - & - & - & - & - \\
\hline & Sem capina & $95,4 \mathrm{a}$ & $74,5 \mathrm{a}$ & $31,7 \mathrm{a}$ & $8,2 \mathrm{a}$ & $9,8 \mathrm{a}$ & $9,3 \mathrm{a}$ & $5,1 \mathrm{a}$ & $17,8 \mathrm{a}$ & $252 a$ \\
\hline \multirow{3}{*}{ Plantio Direto } & Filme de polietil. & - & - & - & - & - & - & - & - & - \\
\hline & \begin{tabular}{|l|} 
Capinado \\
\end{tabular} & - & - & - & - & - & - & - & - & - \\
\hline & Sem capina & $\mathrm{Ob}$ & $75,5 \mathrm{a}$ & $0,5 b$ & $1,2 b$ & $1,2 b$ & $3,3 b$ & $13 a$ & $2,4 \mathrm{~b}$ & $96 \mathrm{~b}$ \\
\hline
\end{tabular}

Nas colunas, letras maiúsculas comparam sistemas de plantio dentro de cada modalidade de manejo de plantas daninhas, pelo teste de Tukey a $5 \%$ de significância $(\mathrm{p} \leq 0,05)$. 
descoberto apresentou densidade populacional de plantas daninhas $300 \%$ superior à do solo com cobertura morta. Segundo Mateus et al. (2004) e Silva et al. (2009), a cobertura do solo com material de origem vegetal reduz significativamente a intensidade de infestação de plantas daninhas e modifica a composição da população infestante devido à barreira física imposta pela palhada e ao não revolvimento do solo.

O consumo de água foi crescente durante todo o ciclo da cultura quando se utilizou o plantio direto, enquanto os tratamentos no sistema de plantio convencional apresentaram comportamento quadrático, com intenso incremento no consumo diário de água até por volta da sexta semana após o transplantio e posterior estabilização (Figura 3).

No desdobramento da interação estratégias de manejo de plantas daninhas dentro dos sistemas de preparo do solo (Tabela 2), observou-se no sistema de plantio direto menor consumo diário de água quando se utilizou o filme de polietileno, seguido do tratamento com capinas. Até a terceira semana após o transplantio não houve diferença no consumo de água entre os tratamentos com e sem capina nesse sistema de plantio, devido à baixa infestação de plantas daninhas. No entanto, a partir da quarta SAT, houve maior consumo de água no tratamento sem capina em relação ao capinado, em razão do crescimento de espécies infestantes de maior porte, como A. spinosus e M. aegyptia, que, mesmo em baixa densidade, demandaram maior quantidade de água.

No sistema de preparo convencional, o filme de polietileno promoveu menor consumo de água durante todo o ciclo da cultura em relação ao manejo com capina, especialmente até a terceira SAT, quando se obteve economia de água da ordem de 50\% (Tabela 2). A intensa infestação de plantas daninhas no plantio convencional (Tabela 1) elevou o consumo de água durante todo o ciclo do meloeiro no sistema de manejo sem capina em relação ao com capina (Tabela 2), demonstrando que as plantas infestantes apresentam grande demanda por água, que resulta em competição com a cultura, caso haja limitação desse fator. Esse fato não foi observado no presente trabalho, visto que a umidade do solo foi mantida sempre acima de $75 \%$ da água disponível total.

Quando se comparam os sistemas de plantio dentro de cada estratégia de manejo de plantas daninhas, verifica-se que não houve variação no consumo de água entre os sistemas de preparo do solo quando se utilizou o filme de polietileno. No entanto, nos tratamentos com capina, observou-se economia considerável de $13 \%$ no consumo de água, no plantio direto, devido à redução da taxa evaporativa da água em função da cobertura do solo com palhada (Tabela 2). Quando não se fez o controle das plantas daninhas, o maior consumo de água foi verificado no plantio convencional, em razão da maior densidade populacional das plantas infestantes.

A economia de água nos tratamentos no sistema de plantio direto e com filme de polietileno no plantio convencional é mais evidente nas primeiras semanas devido à maior importância da evaporação nesse período, conforme pode ser evidenciado na Figura 4, onde se observa, até a quinta semana após o transplantio, redução no consumo

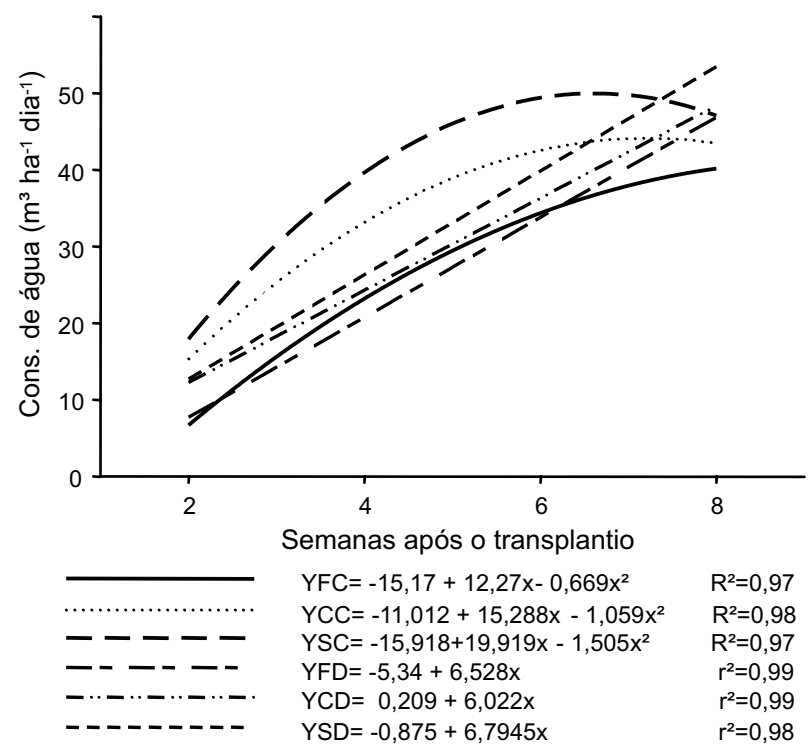

Figura 3 - Consumo diário de água nos diferentes períodos de crescimento (semanas após o transplantio) para os tratamentos com filme de polietileno no plantio convencional (FC), capinado no plantio convencional (CC), sem capina no plantio convencional (SC), filme de polietileno no plantio direto (FD), capinado no plantio direto (CD) e sem capina no plantio direto (SD). Mossoró-RN, 2008. 
Tabela 2 - Consumo diário de água $\left(\mathrm{m}^{3}\right.$ ha $\left.\mathrm{a}^{-1}\right)$ nos diferentes períodos de crescimento (semanas) e consumo total de água meloeiro $\left(\mathrm{m}^{3} \mathrm{ha}^{-1}\right)$, em função dos sistemas de plantio convencional e plantio direto e manejo de plantas daninhas. Mossoró-RN, UFERSA, 2008

\begin{tabular}{|c|c|c|c|c|c|c|c|c|c|}
\hline \multirow{2}{*}{$\begin{array}{l}\text { Sistema } \\
\text { de plantio }\end{array}$} & \multirow{2}{*}{$\begin{array}{l}\text { Sistema de } \\
\text { manejo }\end{array}$} & \multicolumn{7}{|c|}{$\begin{array}{c}\text { Consumo diário }\left(\mathrm{m}^{3} \mathrm{ha}^{-1} \mathrm{dia}^{-1}\right) \\
\text { Períodos (semanas) }\end{array}$} & \multirow{2}{*}{$\begin{array}{l}\text { Cons. total } \\
\left(\mathrm{m}^{3} \mathrm{ha}^{-1}\right)\end{array}$} \\
\hline & & 2 & 3 & 4 & 5 & 6 & 7 & 8 & \\
\hline \multirow{3}{*}{$\begin{array}{l}\text { Plantio } \\
\text { Conv. }\end{array}$} & $\begin{array}{l}\text { Filme de } \\
\text { polietileno }\end{array}$ & $7,74 \mathrm{cA}$ & $13,39 \mathrm{cA}$ & $23,51 \mathrm{cA}$ & $30,65 \mathrm{cA}$ & $35,71 \mathrm{cA}$ & $35,42 \mathrm{cB}$ & $41,07 \mathrm{cB}$ & $1.312,50 \mathrm{cA}$ \\
\hline & Com capina & $15,18 \mathrm{bA}$ & $27,08 \mathrm{bA}$ & $30,36 \mathrm{bA}$ & $38,99 \mathrm{bA}$ & $44,05 \mathrm{bA}$ & $44,44 \mathrm{bA}$ & $42,86 \mathrm{bB}$ & $1.700,70 \mathrm{bA}$ \\
\hline & Sem Capina & $19,05 \mathrm{aA}$ & $30,06 \mathrm{aA}$ & $37,39 \mathrm{aB}$ & $44,64 \mathrm{aA}$ & $52,38 \mathrm{aA}$ & $51,39 \mathrm{aA}$ & $45,24 \mathrm{aB}$ & $1.863,89 \mathrm{aA}$ \\
\hline Média & - & 13,99 & 23,51 & 30,42 & 38,10 & 44,05 & 43,75 & 43,06 & $1.625,70$ \\
\hline \multirow{3}{*}{$\begin{array}{l}\text { Plantio } \\
\text { Direto }\end{array}$} & $\begin{array}{l}\text { Filme de } \\
\text { polietileno }\end{array}$ & $8,11 \mathrm{bA}$ & $13,39 \mathrm{bA}$ & $20,83 \mathrm{cB}$ & $28,42 \mathrm{cB}$ & $33,26 \mathrm{bB}$ & $39,76 \mathrm{bA}$ & $47,32 \mathrm{bA}$ & $1.337,67 \mathrm{cA}$ \\
\hline & Com capina & $12,80 \mathrm{aB}$ & $17,26 \mathrm{aB}$ & $25,00 \mathrm{bB}$ & $30,65 \mathrm{bB}$ & $34,52 \mathrm{bB}$ & $43,98 \mathrm{bA}$ & $48,02 \mathrm{bA}$ & $1.485,55 \mathrm{bB}$ \\
\hline & Sem Capina & $12,80 \mathrm{aB}$ & $17,26 \mathrm{aB}$ & $29,17 \mathrm{aA}$ & $33,04 \mathrm{aB}$ & $37,50 \mathrm{aB}$ & $50,93 \mathrm{aA}$ & $50,99 \mathrm{aA}$ & $1.621,76 \mathrm{aB}$ \\
\hline Média & - & 11,24 & 15,97 & 25,00 & 30,70 & 35,09 & 44,89 & 48,78 & $1.481,69$ \\
\hline $\mathrm{CV}(\%)$ & - & 2,36 & 0,64 & 1,28 & 1,96 & 2,18 & 1,67 & 0,21 & 0,14 \\
\hline
\end{tabular}

Nas colunas, letras minúsculas comparam as modalidades de manejo de plantas daninhas dentro de cada sistema de plantio e letras maiúsculas comparam sistemas de plantio dentro de cada modalidade de manejo de plantas daninhas, pelo teste de Tukey a $5 \%$ de significância (p $\leq$ $0,05)$.

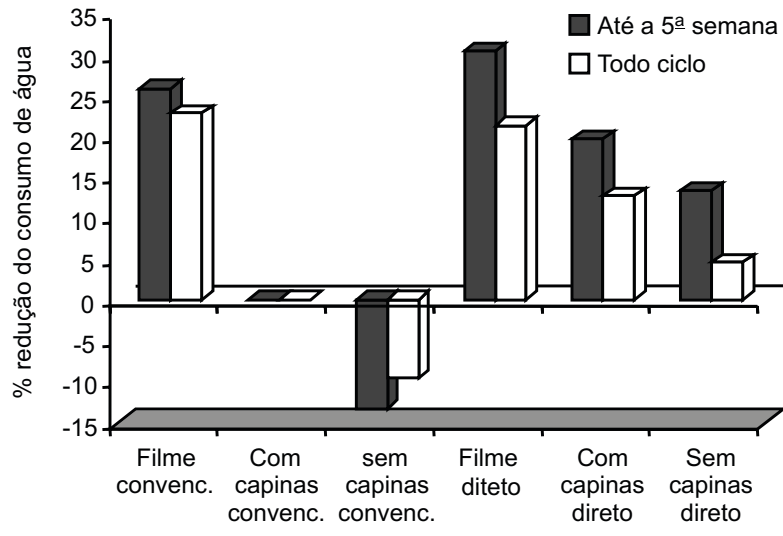

Figura 4 - Economia de água para os tratamentos com filme de polietileno, com capina e sem capina nos sistemas de plantio convencional e plantio direto, em relação ao tratamento com capina no plantio convencional. Mossoró-RN, UFERSA, 2008

de água de 26, 31 e 20\%, respectivamente, para os tratamentos com filme de polietileno no plantio convencional, filme de polietileno no plantio direto e plantio direto com capina, em relação ao tratamento com capina no plantio convencional. A cobertura do solo proporcionou redução da perda de água por evaporação, em relação ao solo sem cobertura, e também foi favorecida pelas condições ambientais, como a combinação de temperatura e velocidade do vento elevadas e baixa umidade relativa do ar (Figura 1A, B e C) durante o período experimental.

A partir da quinta semana, com o crescimento das plantas, houve aumento no consumo de água, ocasionado pela elevação da taxa transpiratória, resultando na redução dos efeitos da cobertura do solo (palhada e filme de polietileno). No final do ciclo da cultura, a economia de água dos tratamentos com filme de polietileno no plantio convencional, filme de polietileno no plantio direto e com capina no plantio direto, em relação ao tratamento com capina no plantio convencional, foi respectivamente de $23 \%\left(388,8 \mathrm{~m}^{3} \mathrm{ha}^{-1}\right), 21 \%\left(363,0 \mathrm{~m}^{3} \mathrm{ha}^{-1}\right)$ e $13 \%\left(215,0 \mathrm{~m}^{3} \mathrm{ha}^{-1}\right)$ (Figura 4). Esses resultados corroboram o de Marouelli et al. (2006), que, trabalhando com tomate para processamento, verificaram que o sistema de plantio direto reduziu o consumo de água em $25 \%$ até 50 dias após o transplantio e em $11 \%$ no ciclo total. 
Segundo Medeiros (2007), a cobertura morta pode promover redução no consumo de água da ordem de 50 a $70 \%$ no período inicial da cultura, por reduzir a taxa de evaporação, podendo assim reduzir a evapotranspiração das culturas, nos estádios iniciais de crescimento. Neste experimento, a irrigação por gotejamento, localizada apenas nas linhas de plantio, proporciona redução de perda de água por evaporação, porém espera-se que a economia de água devido à cobertura do solo seja ainda maior quando se utiliza a irrigação em área total.

Para as características relacionadas à produtividade comercial e total de frutos, houve efeito significativo da interação sistemas de preparo do solo e estratégias de manejo de plantas daninhas (Tabela 3). O sistema de plantio direto apresentou produtividade de frutos comercializáveis e total equivalente à do sistema de plantio convencional, na estratégia de manejo com capinas. Quando se empregou o filme de polietileno, a produtividade foi maior no plantio direto. Na ausência de capinas, o plantio direto se destacou em relação ao plantio convencional devido à grande infestação das plantas daninhas neste último, que proporcionou perda total na produção de frutos comercializáveis.

Não houve variação na produtividade comercializável e total entre as estratégias de manejo de plantas daninhas com capina e cobertura do solo com filme de polietileno nos dois sistemas de preparo do solo. No plantio direto, apesar da baixa infestação de plantas daninhas, o tratamento sem capina apresentou produtividade inferior à do capinado, com redução de $35 \%$ na produção de frutos comercializáveis em relação ao tratamento com capina (Tabela 3). No plantio convencional, o tratamento sem capina, apesar de ter elevado em $9,6 \%$ o consumo de água em relação ao capinado (Figura 3), não produziu frutos comercializáveis (Tabela 3), evidenciando a maior interferência das infestantes nesse sistema.

Os resultados obtidos corroboram o de Tomaz (2008), que não verificou variação na produtividade de frutos comercializáveis nos sistemas de plantio direto e convencional com capina. Esse autor constatou também 100\% de perda na produção comercializável, no plantio convencional sem capina.

Com relação à eficiência no uso da água (EUA), observa-se que nos dois sistemas de plantio a cobertura do solo com filme de polietileno proporcionou menor consumo de água por quilograma de fruto produzido em relação aos sistemas de manejo com capina e, principalmente, aos sem capina (Tabela 3). $\mathrm{Na}$ estratégia de manejo com capinas no plantio convencional, a redução da EUA em $17,3 \%$ em relação ao filme de polietileno devese ao aumento do consumo de água, visto que não houve redução na produtividade, ao passo que no plantio direto capinado o menor valor da EUA, com redução de $21,9 \%$ em relação ao filme de polietileno, deve-se principalmente à alta produtividade obtida por esta estratégia de manejo.

Tabela 3 - Produtividade de frutos e eficiência no uso da água no meloeiro, em função dos sistemas de plantio e estratégias de manejo de plantas daninhas. Mossoró-RN, UFERSA, 2008

\begin{tabular}{|l|l|c|c|c|c|}
\hline \multirow{2}{*}{$\begin{array}{c}\text { Sistema de } \\
\text { plantio }\end{array}$} & \multicolumn{1}{|c|}{ Sistema de manejo } & \multirow{2}{*}{$\begin{array}{c}\text { Produtividade } \\
\text { comercial } \\
\left(\mathrm{t} \mathrm{ha}^{-1}\right)\end{array}$} & $\begin{array}{c}\text { Produtividade } \\
\text { Total } \\
\left(\mathrm{t} \mathrm{ha}^{-1}\right)\end{array}$ & \multicolumn{2}{|c|}{ Eficiência de uso da água $\left(\mathrm{kg} \mathrm{m}^{-3}\right)$} \\
\cline { 4 - 6 } & & $26,60 \mathrm{aB}$ & $29,26 \mathrm{aB}$ & $20,27 \mathrm{aB}$ & $22,29 \mathrm{aB}$ \\
\hline \multirow{3}{*}{$\begin{array}{l}\text { Plantio } \\
\text { Convenc. }\end{array}$} & Filme de polietileno & $30,20 \mathrm{aA}$ & $31,41 \mathrm{aA}$ & $17,65 \mathrm{bB}$ & $18,47 \mathrm{bA}$ \\
\cline { 2 - 6 } & Capinado & $0,00 \mathrm{bB}$ & $2,99 \mathrm{bB}$ & $0,00 \mathrm{cB}$ & $1,61 \mathrm{cB}$ \\
\cline { 2 - 6 } & Sem capina & $34,40 \mathrm{aA}$ & $35,20 \mathrm{aA}$ & $25,58 \mathrm{aA}$ & $26,18 \mathrm{aA}$ \\
\hline \multirow{4}{*}{ Plantio Direto } & Filme de polietileno & $29,71 \mathrm{aA}$ & $30,35 \mathrm{aA}$ & $20,01 \mathrm{bA}$ & $20,43 \mathrm{bA}$ \\
\cline { 2 - 6 } & Capinado & $18,91 \mathrm{bA}$ & $22,07 \mathrm{bB}$ & $11,66 \mathrm{cA}$ & $13,61 \mathrm{cA}$ \\
\cline { 2 - 6 } & Sem capina & 14,31 & 12,47 & 14,20 & 13,16 \\
\hline
\end{tabular}

Nas colunas, letras minúsculas comparam as modalidades de manejo de plantas daninhas dentro de cada sistema de plantio e letras maiúsculas comparam sistemas de plantio dentro de cada modalidade de manejo de plantas daninhas, pelo teste de Tukey $(\mathrm{p} \leq 0,05)$. 
Quando não capinada, a cultura do melão teve a EUA influenciada negativamente pelo aumento no consumo de água (Tabela 2) e redução na produtividade (Tabela 3 ), com efeitos mais danosos no plantio convencional devido à alta infestação de plantas daninhas, as quais causaram perda total na produção comercializável, evidenciando a interferência por outros fatores, como competição por luz, nutrientes, espaço físico e provável efeito alelopático, uma vez que a água não foi fator limitante neste trabalho. No plantio direto, apesar da menor infestação, a grande influência negativa foi exercida pelas plantas infestantes, que promoveram redução da EUA em $33,4 \%$ em relação ao tratamento mantido sem a presença das espécies infestantes (Tabela 2).

Quando se comparam os dois sistemas de preparo do solo em cada estratégia de manejo de plantas daninhas, verifica-se que o sistema de plantio direto proporcionou melhor EUA que o preparo convencional em todas estratégias de manejo, o que se deve à combinação da economia de água com a boa produtividade. No caso dos tratamentos com a cobertura do solo com filme de polietileno no sistema de plantio direto, esse benefício pode ser atribuído, também, ao efeito da palhada, que atua como isolante térmico, uma vez que a temperatura máxima diária do ar durante o período de condução do experimento foi de aproximadamente $34{ }^{\circ} \mathrm{C}$ (Figura 1). Segundo IbarraJiménez et al. (2008), a cobertura do solo com filme de polietileno preto promove elevação da temperatura do solo em $5,2{ }^{\circ} \mathrm{C}$, quando comparado ao solo sem cobertura. Tomaz (2008) também constatou efeito positivo da combinação do filme de polietileno mais plantio direto na palha na produção de melão, em relação ao filme de polietileno no plantio convencional.

Nos tratamentos com capina, a melhor EUA se deve à redução no consumo de água, visto que a produtividade nos dois sistemas de plantio foi semelhante, ao passo que na ausência de capinas o fator determinante na redução da EUA no plantio convencional foi a maior interferência das plantas daninhas, que resultou em redução drástica na produtividade em relação ao plantio convencional.

A eficiência do uso da água refere-se ao rendimento total da colheita por quantidade de água utilizada, podendo ser melhorada através do uso de estratégias que permitam aumento da produtividade, como utilização adequada de insumos e práticas culturais, e principalmente do uso de técnicas que permitam reduzir as perdas de água, pela adoção criteriosa do sistema e manejo de irrigação, além da utilização de estratégias que favoreçam o armazenamento de água no solo, através do aumento da infiltração e da redução da taxa de evaporação. Isso ficou evidente neste trabalho, quando se observaram melhores valores de EUA obtidos com o solo coberto com o filme de polietileno nos dos sistemas de plantio e com palhada no sistema de plantio direto.

Na cultura do repolho, Carvalho et al. (2011) verificaram que o emprego da cobertura morta elevou a produtividade e a EUA, sobretudo quando se estendeu o turno de rega de 12 para 48 horas. Segundo Lima et al. (2006), a utilização da cobertura morta possibilita maior economia de energia e redução dos volumes hídricos aplicados, especialmente para o pequeno produtor nas condições do semiárido, devido à escassez de água nessa região.

Diante do exposto, conclui-se que o sistema de plantio direto na palha reduziu a densidade populacional e a massa seca acumulada pelas plantas daninhas em 86,7 e $61 \%$, respectivamente, em relação ao plantio convencional, e a interferência destas reduziu a produtividade comercial em $100 \%$ no plantio convencional e $36,35 \%$ no direto, além de aumentar o consumo de água nos dois sistemas de plantio. A cobertura do solo com filme de polietileno no plantio convencional e no plantio direto e a palhada no plantio direto reduziram o consumo de água em $23 \%\left(388,8 \mathrm{~m}^{3} \mathrm{ha}^{-1}\right), 21 \%$ $\left(363,0 \mathrm{~m}^{3} \mathrm{ha}^{-1}\right)$ e $13 \%\left(215,0 \mathrm{~m}^{3} \mathrm{ha}^{-1}\right)$, respectivamente, em relação ao tratamento com capinas no plantio convencional, aumentando a eficiência no uso da água.

\section{LITERATURA CITADA}

ALLEN, R. G. et al. Crop evapotranspiration: guidelines forcomputing crop water requirements. Rome: FAO, 1998 297 p. (FAO, irrigation and Drainage Paper, 56)

BATISTA, P. F. et al. Produção e qualidade de frutos de melão submetidos a dois sistemas de irrigação. Hortic. Bras., v. 27 , n. 2, p. 246-250, 2009.

Planta Daninha, Viçosa-MG, v. 30, n. 3, p. 547-556, 2012 
CARVALHO, J. F. et al. Produtividade do repolho utilizando cobertura morta e diferentes intervalos de irrigação com água moderadamente salina. R. Bras. Eng. Agríc. Amb., v. 15, n. 3, p. 256-263, 2011.

DOORENBOS, J.; KASSAM, A. H. Efectos del água em al rendimiento de los cultivos. Roma: FAO 1979. 212 p.

EMPRESA BRASILEIRA DE PESQUISAAGROPECUÁRIA

- EMBRAPA. Centro Nacional de Pesquisa do Solo.

Sistema brasileiro de classificação de solos. Brasília:

Serviço de Produção de Informação, 1999. 412 p.

FERNANDES, D. Interferência de plantas daninhas na produção e qualidade de frutos de melão nos sistemas de plantio direto e convencional. 2010. 62 f. Dissertação (Mestrado em Fitotecnia) - Universidade Federal Rural do Semi-Árido, Mossoró, 2010.

FREITAS, F. C. L. et al. Comportamento de cultivares de milho no consórcio com Brachiaria brizantha na presença e ausência de foransulfuron + iodosulfuron-methyl para o manejo da forrageira. Planta Daninha, v. 26, n. 1, p. 215-221, 2008

FREITAS, P. S. L. et al. Efeito da cobertura de resíduo da cultura do milho na evaporação de água do solo. R. Bras. Eng. Agríc. Amb., v. 8, n. 1, p. 85-91, 2004

IBARRA-JIMÉNEZ, L. et al. Photosynthesis, soil temperature and yield of cucumber as affected by colored plastic mulch. Acta Agric. Scandinavica Section B - Soil Plant Sci., v. 58, p. 372-378, 2008

LIMA, P. A. et al. Efeito do manejo da irrigação com água moderadamente salina na produção de pimentão. R. Bras. Ci. Agr., v. 1, n. 1, p. 73-80, 2006.

MAROUELLI, W. A. et al. Uso de água e produção de tomateiro para processamento em sistema de plantio direto com palhada. Pesq. Agropec. Bras., v. 41, n. 9, p. 1399-1404, 2006.
MATEUS, G. P.; CRUSCIOL, C. A. C.; NEGRISOLI, E. Palhada do sorgo de guiné gigante no estabelecimento de plantas daninhas em área de plantio direto. Pesq. Agropec. Bras., v. 39, n. 6, p. 539-542, 2004

MEDEIROS, J. F. Uso racional e preservação de recursos hídricos na agricultura. In: FREITAS, F. C. L. et al. SIMPÓSIO SOBRE MANEJO DE PLANTAS DANINHAS NO SEMI-ÁRIDO, 1., 2007, Mossoró. Anais... Mossoró: 2007. p. $35-52$

SANTOS, C. A. B. et AL. Efeito de coberturas mortas vegetais sobre o desempenho da cenoura em cultivo orgânico.Hortic. Bras., v. 29, n. 1, p. 103-107, 2011.

SILVA, A. C. et al. Consórcio entre feijão e Brachiaria brizantha sob doses reduzidas de graminicida.

Planta Daninha, v. 24, n. 1, p. 771-76, 2006

SILVA, A. C. et al. Manejo integrado de plantas daninhas em hortaliças. In: FREITAS, F. C. L. et al. SIMPÓSIO SOBRE MANEJO DE PLANTAS DANINHAS NO SEMI-ÁRIDO, 1., 2007, Mossoró, 2007. Anais... Mossoró, 2007. p. 199211.

SILVA, A. C.; HIRATA, E. K.; MONQUERO, P. A. Produção de palha e supressão de plantas daninhas por plantas de cobertura, no plantio direto do tomateiro. Pesq. Agropec. Bras., v. 44, n. 1, p. 22-28, 2009.

TOMAZ, H. V. Q. Manejo de plantas daninhas, crescimento e produtividade do meloeiro em sistemas de plantio direto e convencional. 2008. 67 f. Dissertação (Mestrado em Fitotecnia) - Universidade Federal Rural do Semi-Árido, Mossoró, 2008.

VIDAL, R. A.; TREZZI, M. M. Potencial da utilização de coberturas vegetais de sorgo e milheto na supressão de plantas daninhas em condição de campo: I-plantas em desenvolvimento vegetativo. Planta Daninha, v. 22, n. 2, p. 217-233, 2004. 